\title{
Influence of deposition temperature on nanocrystalline CdS thin films: Application in Solar Cells as Antireflection Coatings
}

\author{
S. M. Patil, P. H. Pawar \\ Z. B. Patil College of Arts, Commerce and Science College, Dhule - 424 002, India \\ *E-mail address: sham_nilima@rediffmail.com
}

\begin{abstract}
Nanocrystalline CdS thin films were successfully prepared using simple chemical bath deposition technique. Cadmium sulphate, thiourea and deionised water were used as starting precursor solution. The prepared thin films were characterized using X-ray diffractogram (XRD), Scanning electron microscope (SEM), elemental composition using energy dispersive spectrophotometer (EDAX) and optical band gap (UV-Spectroscopy).X-ray diffractogram reveals that present of cubic and hexagonal phase. The thickness, crystallite size and grain size were observed to be increase with increase operating temperature of bath while optical band gap energy slightly decreases. Effect of deposition temperature on physical, structural, microstructural, electrical and optical properties of these films was studied and presented in the present investigation. Prepared thin films shows good response towards photoconducting in presence and absent of light.
\end{abstract}

Keywords: CdS thin films; XRD; SEM; TEP and electrical conductivity

\section{INTRODUCTION}

Semiconducting thin films of CdS are used in commercial photocells and also as window material for $\mathrm{CdS} / \mathrm{CdTe}$ solar cells continues as a subject of intense research in order to obtain cells with higher efficiencies [1]. CdS thin films are regarded as one of the most promising materials for heterojunction thin film solar cells. Wide band $\mathrm{CdS}(\mathrm{Eg}=2.42 \mathrm{eV})$ has been used as the window material together with several semiconductors such as CdTe, $\mathrm{Cu}_{2} \mathrm{~S}$ and $\mathrm{InP}$ with 14-16\% efficiency [2-5]. Various techniques, have been employed to prepare CdS thin films such as thermal evaporation [3], sputtering [4], molecular beam epitaxy [5], spray pyrolysis [6], chemical bath deposition [7]. Chemical bath deposition is a method of growing thin films of certain materials on a substrate immersed in an aqueous bath containing appropriate reagents at temperatures ranging from room temperature to $100{ }^{\circ} \mathrm{C}$. It has been identified as a low process suitable for the preparation of large area thin films [8]. Chemical bath deposition (CBD) method has attracted much attention since it is conformed as a simple and promising technique to obtain device quality films. CBD is a simple which is also used to deposited the semiconductor on photovoltaic device. The CBD method appears suitable for large area industrial process because it is the least expensive and a low temperature method. The deposited films samples were characterized by XRD, SEM, UV- 
spectroscopy and electrical techniques. This work investigate effect of deposition temperature on physical, structural, microstructural, electrical and optical properties of these films .The films were characterized using different analytical techniques. The results were discussed and interpreted in the present investigations.

\section{EXPERIMENTAL WORK}

\section{1. Substrate cleaning}

The substrate cleaning is very important in the deposition of thin films. Commercially available glass slides with a size of $25 \mathrm{~mm} \times 25 \mathrm{~mm} \times 1 \mathrm{~mm}$ were washed using soap solution and subsequently kept in hot chromic acid and then cleaned with deionized water followed by rinsing in acetone. Finally, the substrates were previously cleaned with deionized water for 20 min and wiped with acetone and stored in a hot oven [11].

\section{2. Preparation of nanocrystalline CdS thin films}

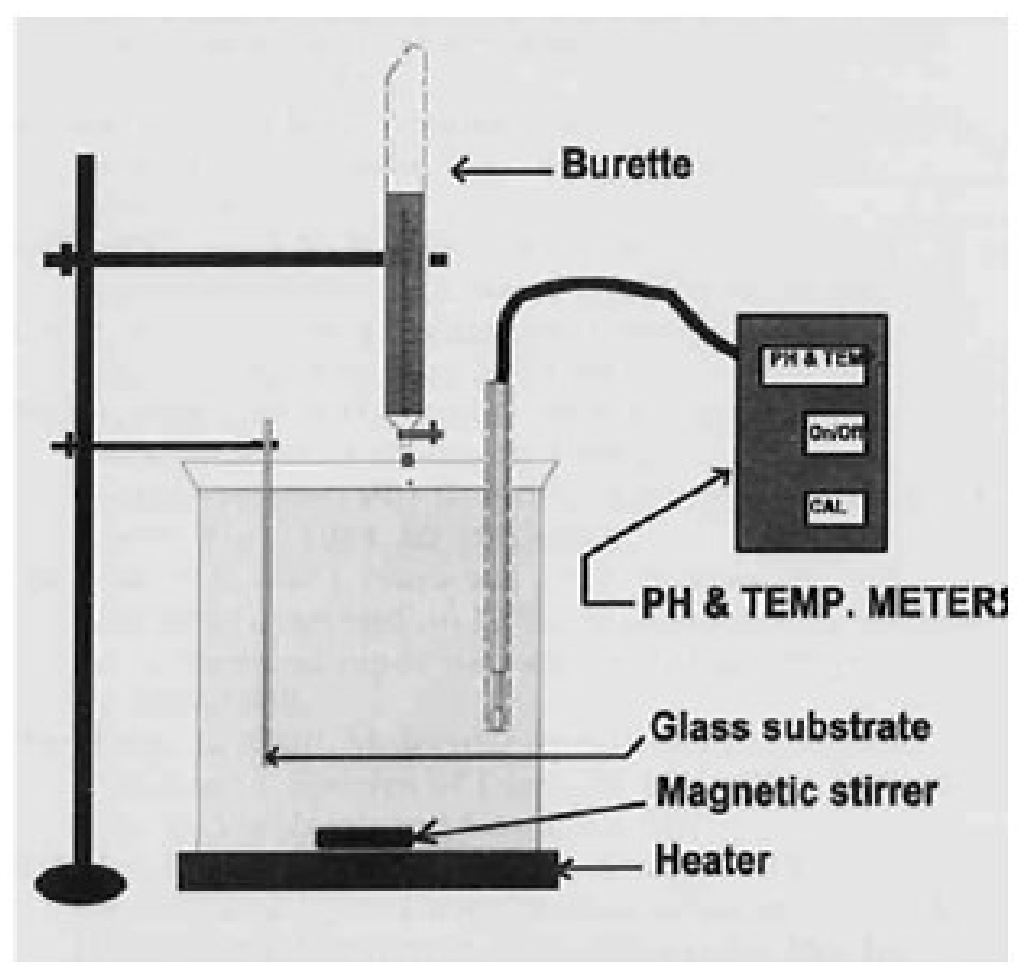

Fig. 1. Chemical bath deposition set up.

The chemical bath deposition technique was used to deposit the thin films of cadmium sulphide on glass substrate (Shows in Fig. 1). The starting materials used were cadmium sulphate and thiourea. Triethanolamine (TEA) was used as a complexing agent. Ammonia solutions were used to adjust $\mathrm{pH}$ of the reaction mixture. In order to obtain good quality of thin films, following parameter were adjust such as time, temperature of deposition and $\mathrm{pH}$ of the solution. The optimum value of time, temperature and $\mathrm{pH}$ were tabulated in Table 1. 
Table 1. Optimum parameter to obtain nanocrystalline $\mathrm{CdS}$ thin films.

\begin{tabular}{|c|c|}
\hline Deposition parameter & Optimum value / item \\
\hline Deposition time & $70 \mathrm{~min}$ \\
\hline $\mathrm{pH}$ & 10 \\
\hline $\begin{array}{c}\text { Concentration of precursor } \\
\text { Cadmium sulphate, Thiourea }\end{array}$ & $0.1 \mathrm{M}$ \\
\hline Solvent & Deionized water \\
\hline Deposition temperature & $60^{\circ} \mathrm{C}, 65^{\circ} \mathrm{C}, 70^{\circ} \mathrm{C}$, and $75^{\circ} \mathrm{C}$, \\
\hline
\end{tabular}

\section{3. Post preparative treatment of $\mathrm{CdS}$ thin films}

The as prepared $\mathrm{CdS}$ thin film samples were fired at $225^{\circ} \mathrm{C}$ for $10 \mathrm{~min}$.

\section{CHARACTERIZATIONS OF THIN FILMS}

\section{1. Physical Properties}

The film thickness was measured by a weight difference method [12-15] in which weight of the sample, area and densities were considered.

\section{2. Structural properties using XRD}

The CdS thin film were characterized by X-ray diffraction ((Miniflex Model, Rigaku, Japan)) using $\mathrm{CuK} \alpha$ radiation with a wavelength, $\lambda=1.542 \AA$. The average grain size of $\mathrm{CdS}$ thin film samples were calculated by using the Scherrer formula

$$
D=0 \cdot 9 \lambda / \beta \cos \theta
$$

where:

$D=$ Average crystallite size

$\lambda=\mathrm{X}$-ray wavelength $(1 \cdot 542 \AA)$

$\beta=$ FWHM of the peak

$\theta=$ Diffraction peak position.

\section{3. Microstructural properties using SEM}

The microstructure and element composition of the films was analyzed using scanning electron microscope coupled with energy dispersive spectrophotometer (JEOL 2300 model, Japan).

\section{4. Optical properties using UV-spectroscopy}

The optical properties of the films were measured using UV-visible-2450 spectrophotometer at room temperature. 


\section{5. Electrical properties}

Electrical conductivity measured using two probe method (SES Instrument Model: PID-210, Model: EHT-11). Thermoelectric power measurement were conducting using TEP setup (Pushpa agencies).

\section{RESULT AND DISCUSSION}

\section{1. Physical properties}

\section{1. 1. Determination of film thickness}

The thickness, sample weight and sample area are related as:

$$
t=M / A \cdot \rho
$$

where:

$M=$ weight of the sample in $g m$,

$\mathrm{A}=$ area of the sample in $\mathrm{cm}^{2}$

$\rho=$ materials density in $\mathrm{gm} \mathrm{cm}^{-3}$

The thickness of the film was $650-705 \mathrm{~nm}$. The values of the film thickness with grain size are given in Figure 2.

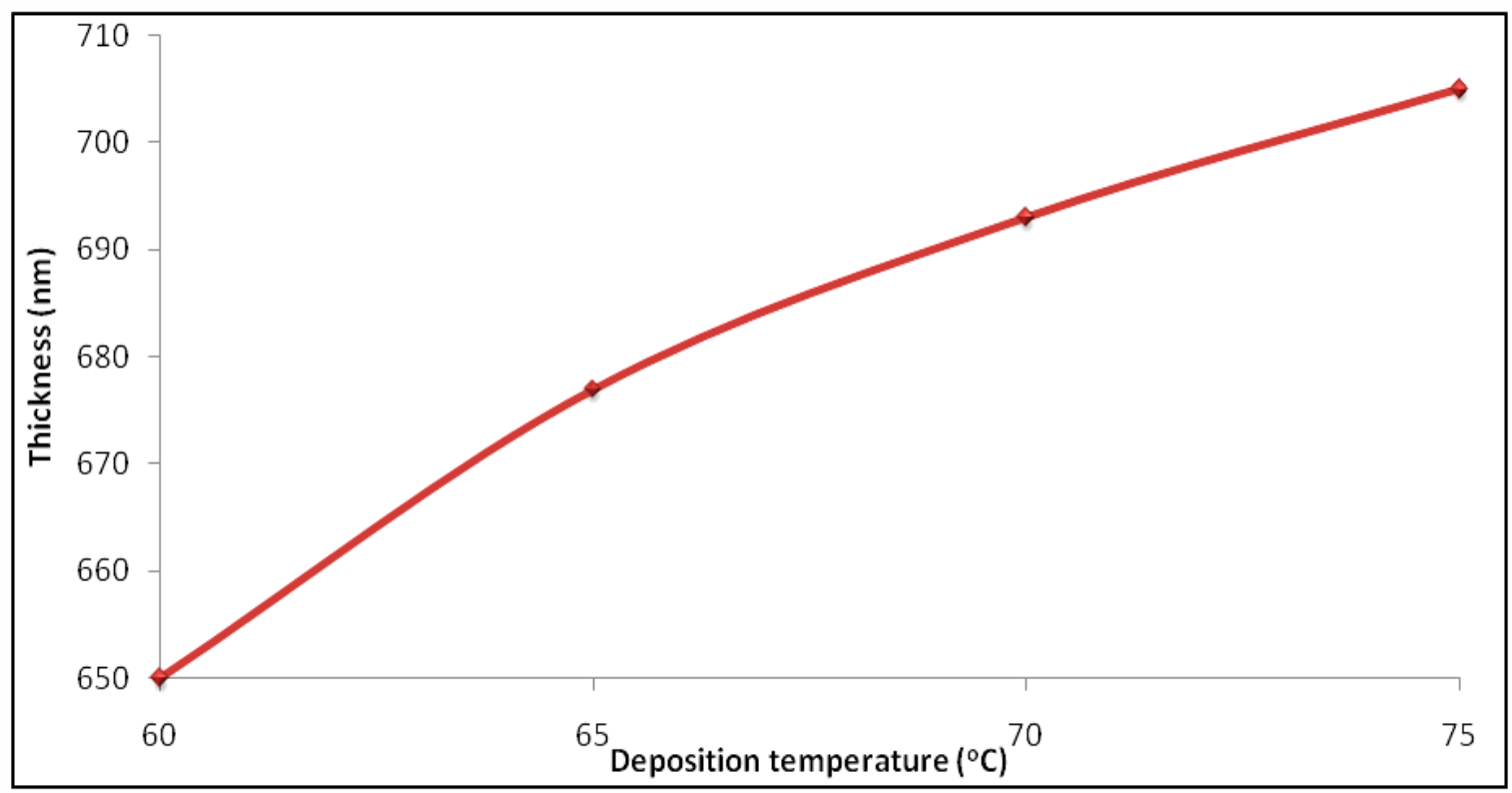

Fig. 2. Thickness of the films as a function of deposition temperature.

The Thickness of the films increases with deposition temperature as shown in Figure 2. The linear increasing thickness with deposition temperature could be due to the change in crystallite size and grain size accompanied with deposition temperature. 


\section{2. Structural properties}

\section{2. 1. Crystal structure and size}

Figure 3 shows the X-ray diffractogram of pattern of the film prepared at different operating temperature $\left(60{ }^{\circ} \mathrm{C}-75^{\circ} \mathrm{C}\right)$. It shows presence of different strong diffraction peaks which confirm mixed phases of cubic and hexagonal CdS formation. The large number of peaks indicates the crystalline nature of the CdS film sample. From the XRD spectrum it is clear that CdS film sample deposited in the cubic and hexagonal phases. The observed dvalues which coincide well with the JCPDS data [16,17]. ' $\mathrm{hkl}$ ' planes of cubic phase is shown in the Fig. 3 with symbol $(\mathrm{C}=$ cubic) faces while the ' $\mathrm{hkl}$ ' planes of hexagonal phase is shown in the symbol $(\mathrm{H}=$ hexagonal $)$ faces. X-ray analysis showed that $\mathrm{CdS}$ films are crystalline in nature with cubic and hexagonal modification.

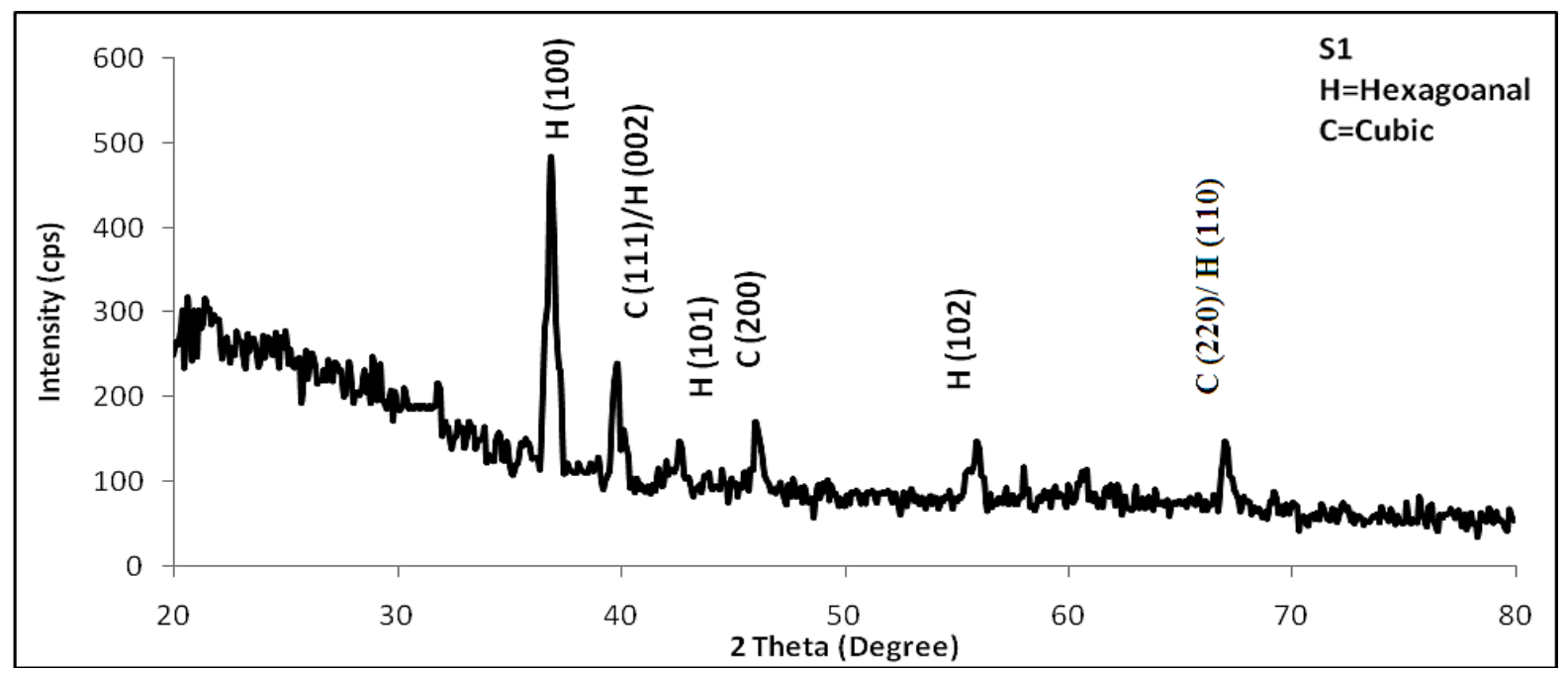

(S1)

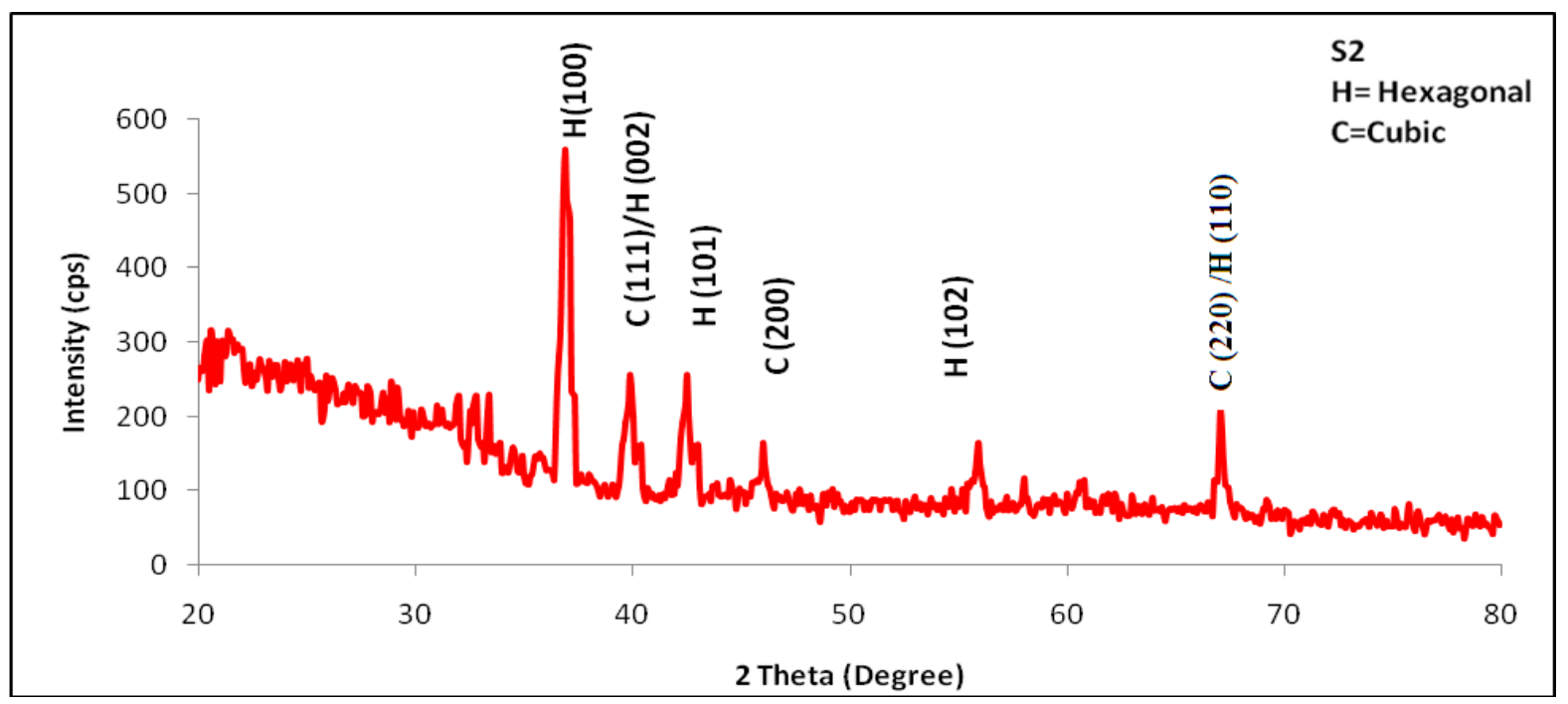

(S2) 


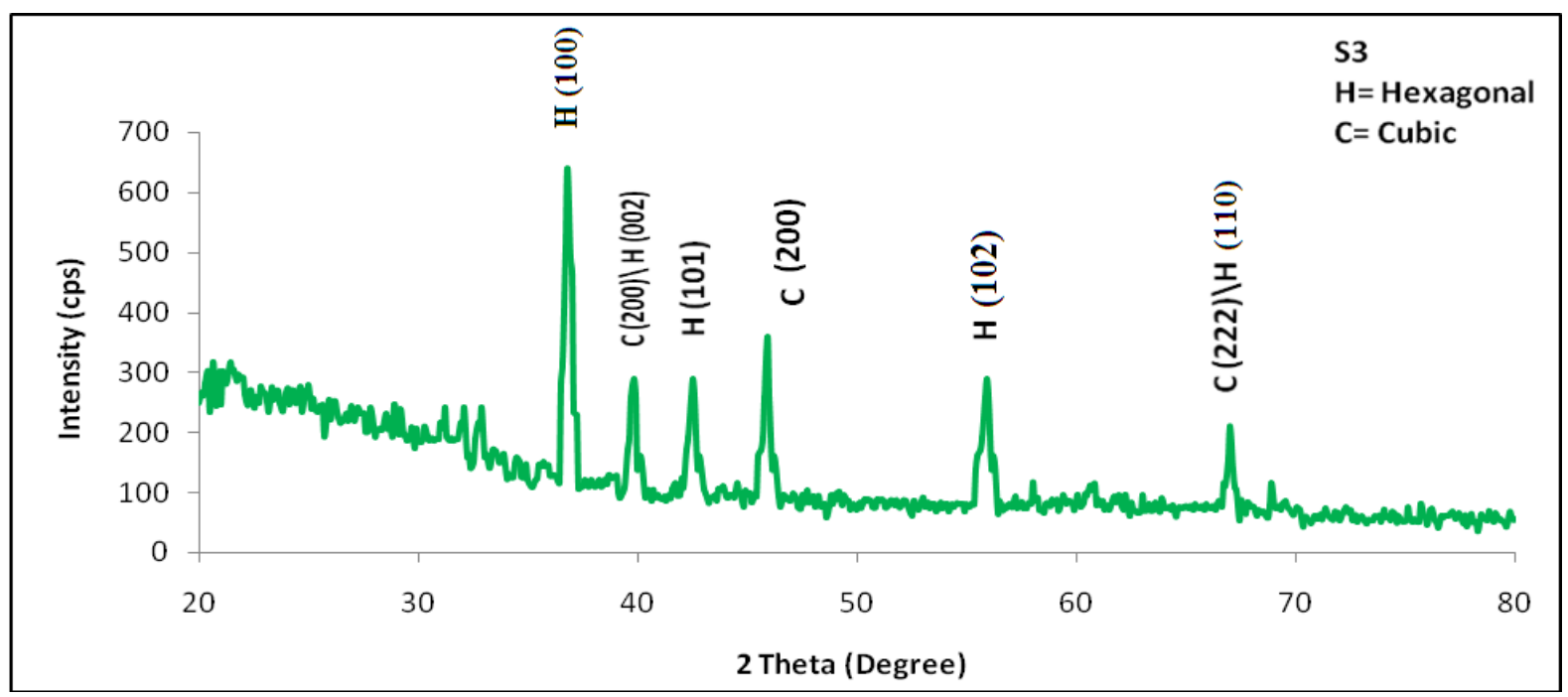

(S3)

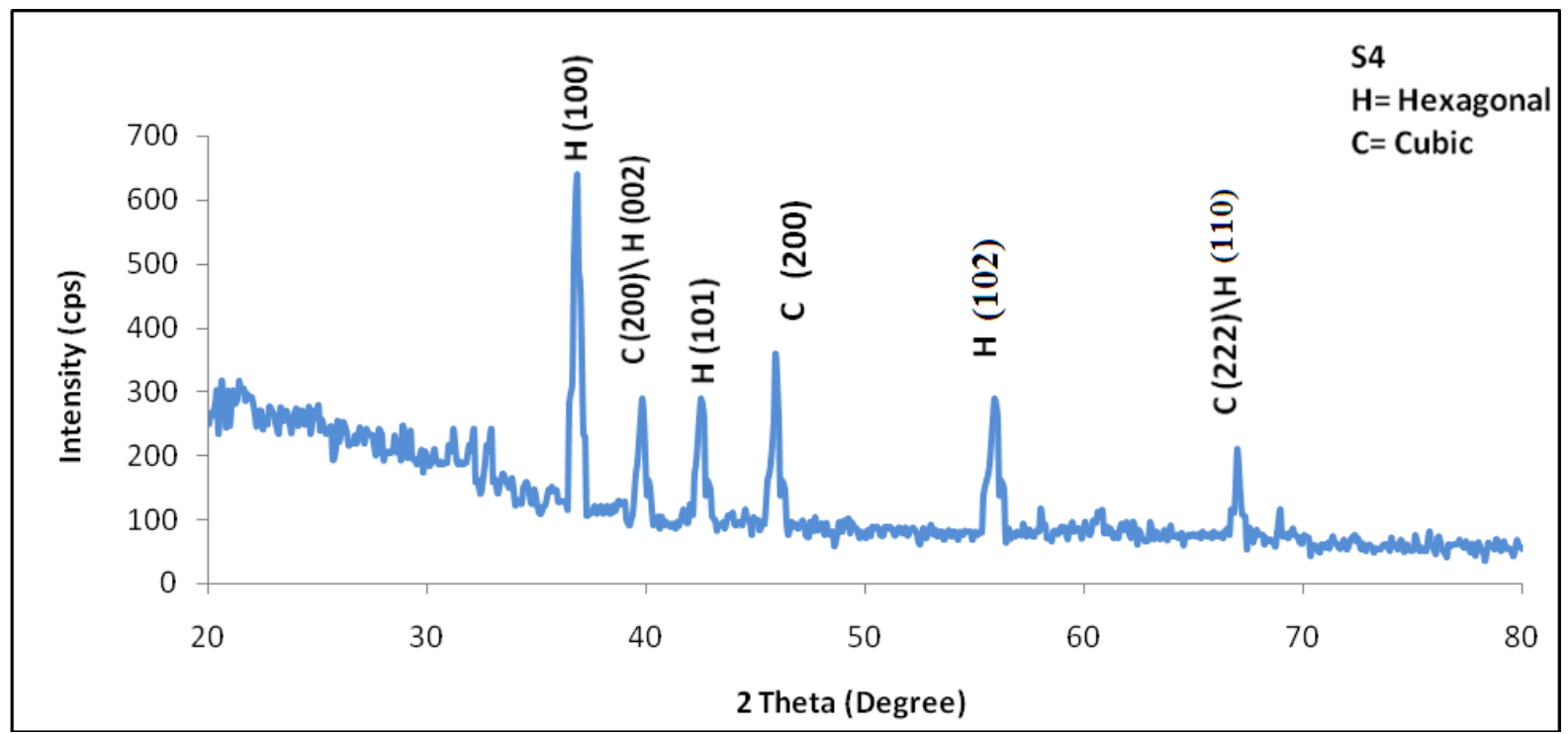

(S4)

Fig. 3. X-ray diffractogram of nanocrystalline CdS thin film samples: S1, S2, S3 and S4.

The increase in the intensity of peak is observed at $40^{\circ}$ due to merging of peaks of cubic and hexagonal phases takes place. Similarly the increase in the intensity of peak is observed at $67^{\circ}$ due to merging of peaks of cubic and hexagonal phases takes place. From the fullwidth at half-maximum of the diffraction peaks, the average sizes of the nanocrystallites (Table 1) have been calculated using the Debye-Scherrer formula [11].

Peak intensity of the films was observed to be maximum for sample (S4) at operating temperature $105^{\circ} \mathrm{C}$. While it is minimum for the film prepared at operating temperature 60 ${ }^{\circ} \mathrm{C}$, due to low deposition temperature. From Fig. 3 as deposition temperature increases, crystallite size increases. These results show that the size of the CdS nanocrystallites depends mainly on the deposition temperature and it increases with increasing the deposition temperature (the size of nanocrystallites change from $23 \mathrm{~nm}$ at $60{ }^{\circ} \mathrm{C}$ to $42 \mathrm{~nm}$ at $105^{\circ} \mathrm{C}$ ). 
This deposition temperature dependence of size may be explained according to that the larger crystallites being more stable than the smaller ones which are formed at the initial deposition time.

The lattice parameters of cubic and hexagonal phases have been calculated by using equation (3) and (4) respectively.

$$
\begin{aligned}
a & =\mathrm{d}(\mathrm{h}+\mathrm{k}+1){ }^{1 / 2} \\
1 / \mathrm{d}^{2}{ }_{\mathrm{hkl}} & =4 / 3\left[\mathrm{~h}^{2}+\mathrm{hk}+\mathrm{k}^{2}\right] / \mathrm{a}^{2}+1^{2} / \mathrm{c}^{2}
\end{aligned}
$$

where' $d$ ' is the interplanar distance and ' $h, k, l$ ' are Miller indices of the lattice planes.

The lattice parameter ' $a$ ' of cubic phase was found to be in the order of $5.848 \AA$. The lattice parameter ' $a$ ' and ' $b$ ' of hexagonal phase were found to be in the order of $4.1338 \AA$ and $7.7127 \AA$ respectively. The structural parameters of Cubic phase are shown in Table 2 while structural parameters of hexagonal phase are shown in Table 3.

\begin{tabular}{|c|c|c|c|c|c|c|c|c|c|}
\hline \multirow{2}{*}{$\begin{array}{l}\text { hkl } \\
\text { plane }\end{array}$} & \multirow{2}{*}{$\begin{array}{c}\text { Standard } \\
\text { d-values } \\
\AA \\
\text { Cubic } \\
\text { phase }\end{array}$} & \multicolumn{4}{|c|}{$\begin{array}{c}\text { Observed d-values } \AA \\
\text { Cubic phase }\end{array}$} & \multicolumn{4}{|c|}{$\begin{array}{c}\text { Cell parameter }(\AA) \\
\text { a } 6.776\end{array}$} \\
\hline & & S1 & S2 & S3 & S4 & S1 & S2 & S3 & $\mathrm{S} 4$ \\
\hline 111 & 3.360 & 3.354 & 3.355 & 3.355 & 3.359 & \multirow{3}{*}{5.846} & \multirow{3}{*}{5.847} & \multirow{3}{*}{5.849} & \multirow{3}{*}{5.848} \\
\hline 200 & 2.900 & 2.899 & 2.896 & 2.897 & 2.998 & & & & \\
\hline 220 & 2.060 & 2.056 & 2.058 & 2.059 & 2.057 & & & & \\
\hline
\end{tabular}

Table 2. Comparison of standard d values with observed d values and cell parameter for cubic phase.

Table 3. Comparison of standard d values with observed d values and cell parameter for hexagonal

\begin{tabular}{|c|c|c|c|c|c|c|c|c|c|}
\hline \multirow{2}{*}{$\begin{array}{l}\text { hkl } \\
\text { plane }\end{array}$} & \multirow{2}{*}{$\begin{array}{c}\text { Standard } \\
\text { d-values } \\
\AA \\
\text { hexagonal } \\
\text { phase }\end{array}$} & \multicolumn{4}{|c|}{$\begin{array}{c}\text { Observed d-values } \AA \\
\text { Cubic phase }\end{array}$} & \multicolumn{4}{|c|}{$\begin{array}{c}\text { Cell parameter }(\AA) \\
\text { a and c }\end{array}$} \\
\hline & & S1 & $\mathrm{S} 2$ & S3 & S4 & S1 & $\mathrm{S} 2$ & $\mathrm{~S} 3$ & S4 \\
\hline 100 & 3.560 & 3.358 & 3.357 & 3.359 & 3.356 & \multirow{5}{*}{$\begin{array}{c}4.13 \\
\text { (a) } \\
7.71 \\
\text { (c) }\end{array}$} & \multirow{5}{*}{$\begin{array}{c}4.12 \\
\text { (a) } \\
7.70 \\
\text { (c) }\end{array}$} & \multirow{5}{*}{$\begin{array}{c}4.13 \\
\text { (a) } \\
7.69 \\
\text { (c) }\end{array}$} & \multirow{5}{*}{$\begin{array}{c}4.14 \\
\text { (a) } \\
7.72 \\
\text { (c) }\end{array}$} \\
\hline 002 & 3.350 & 3.347 & 3.349 & 3.346 & 3.348 & & & & \\
\hline 101 & 3.140 & 3.138 & 3.136 & 3.137 & 3.139 & & & & \\
\hline 102 & 2.450 & 2.449 & 2.447 & 2.448 & 2.446 & & & & \\
\hline 110 & 2.070 & 2.068 & 2.069 & 2.067 & 2.066 & & & & \\
\hline
\end{tabular}
phase. 


\section{3. Optical properties study using UV-Spectroscopy}

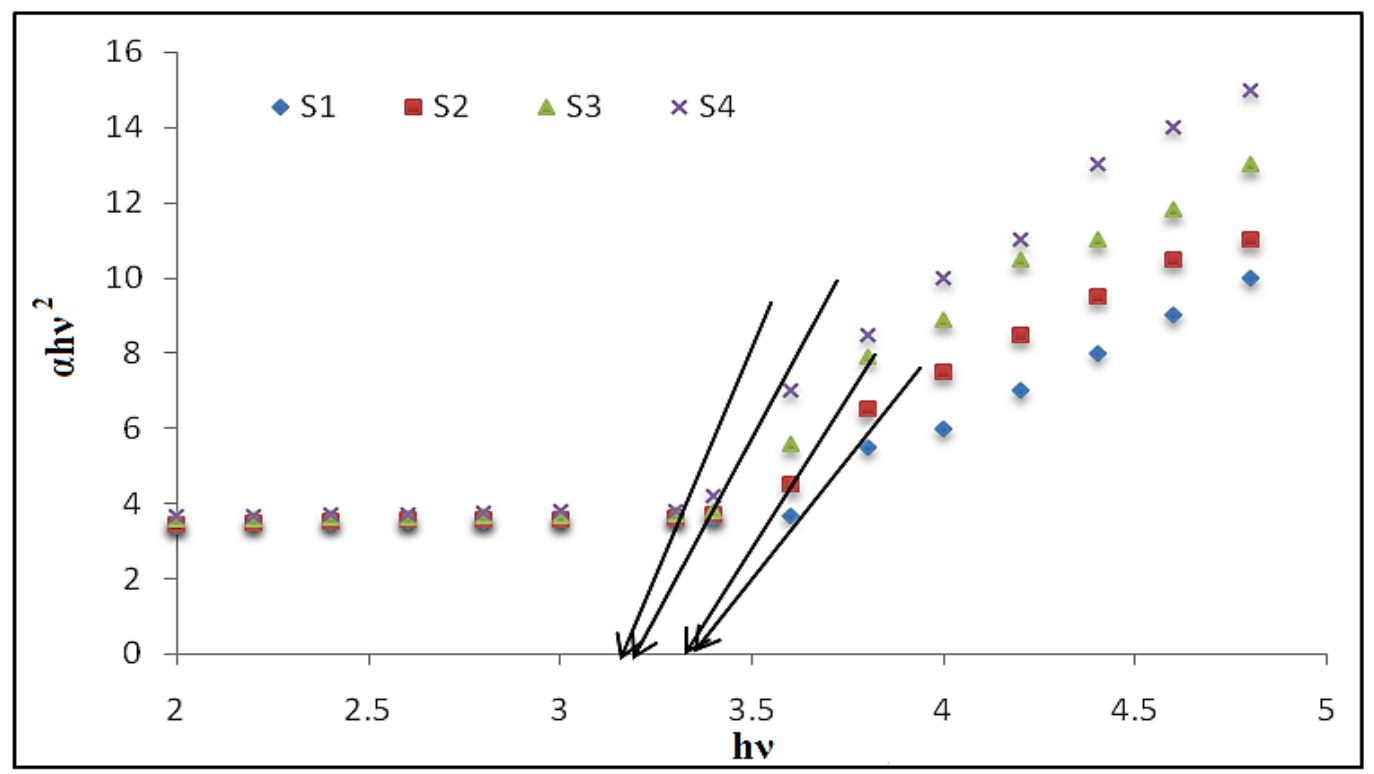

Fig. 4. Plot of the $(\alpha h v)^{2}$ vs photon energy $(h v)$ for nanocrystalline CdS thin film.

The optical energy band gap of CdS thin film was estimated from optical absorption measurement. The optical absorption spectrum for the CdS thin film is recorded in the wavelength range of 300-900 $\mathrm{nm}$ at room temperature shown in Fig 4. The optical absorption data were analyzed using the following classical relation of optical absorption in semiconductor near band edge:

$$
\alpha h v=A(h v-E g)^{n}
$$

where $\alpha$ is absorption coefficient, $A$ is constant, $E \mathrm{~g}$ is the separation between bottom of the conduction band and top of the valence band, $h v$ the photon energy and $n$ is a constant.

The value of $n$ depends on the probability of transition; it takes values as $1 / 2,3 / 2,2$ and 3 for direct allowed, direct forbidden, indirect allowed and indirect forbidden transition respectively. Thus, if plot of $(\alpha h v)^{2}$ versus $(h v)$ is linear the transition is direct allowed. Extrapolation, of the straight-line portion to zero absorption coefficient $(\alpha=0)$, leads to estimation of band gap energy $(E \mathrm{~g})$ values. Fig. 4 shows variation of $(\alpha h v)^{2}$ as a function of photon energy $(h v)$. The band gap energy, calculated from the spectrum for film was tabulated in Table 3. This suggests the decrease in the band gap energy (Eg) with increasing the deposition time. It is strongly observed that the CdS thin films exhibit the least reflectance for almost all wavelengths. From the above studies, it is believed that the $\mathrm{CdS}$ thin films may be used as an antireflection coating material for thin film solar cells.

\section{4. Microstructural Properties}

\section{4. 1. Scanning electron microscope}

Fig. 5 shows the SEM images of CdS thin film samples S1, S2, S3 and S4 respectively. 


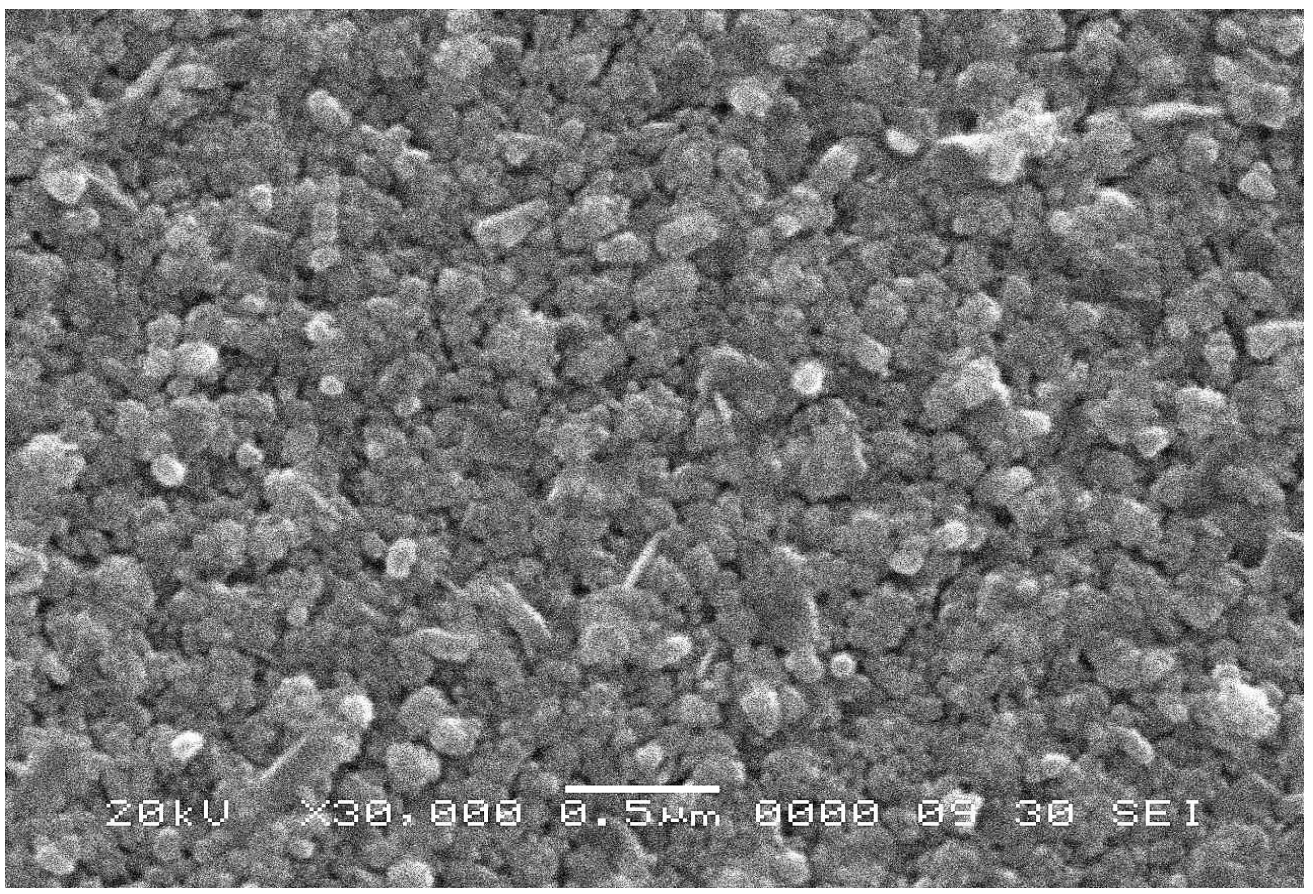

(a)

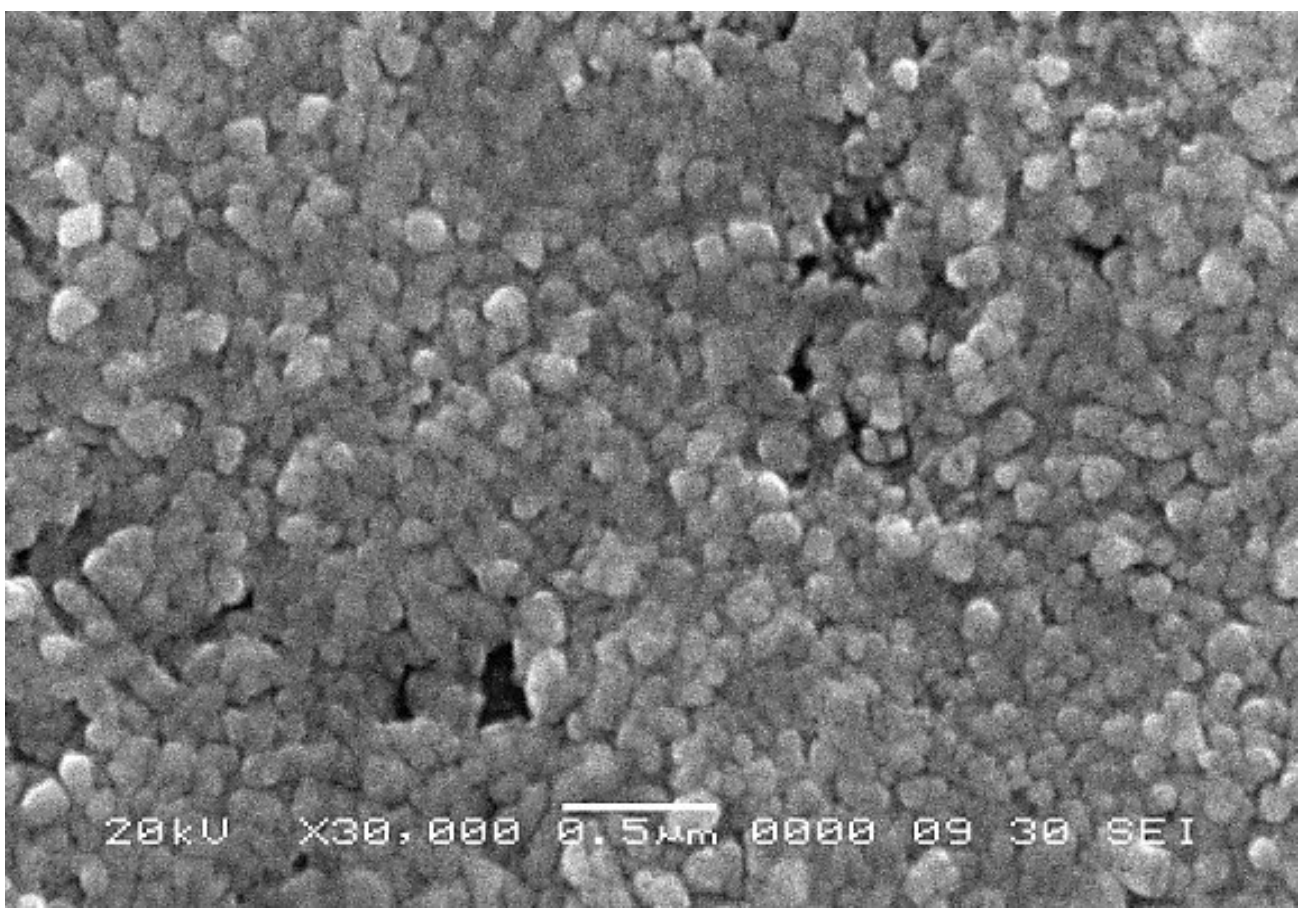

(b) 


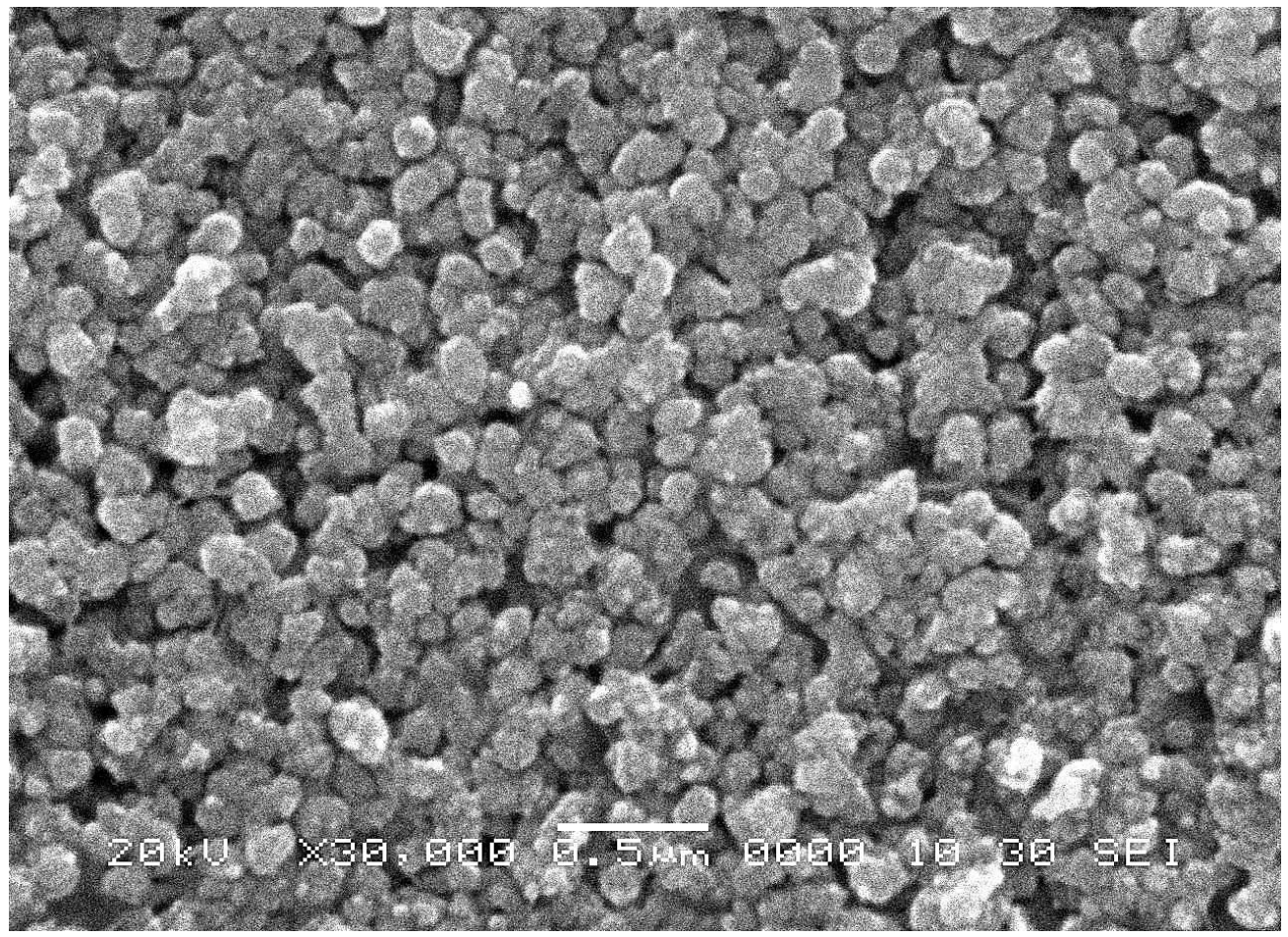

(c)

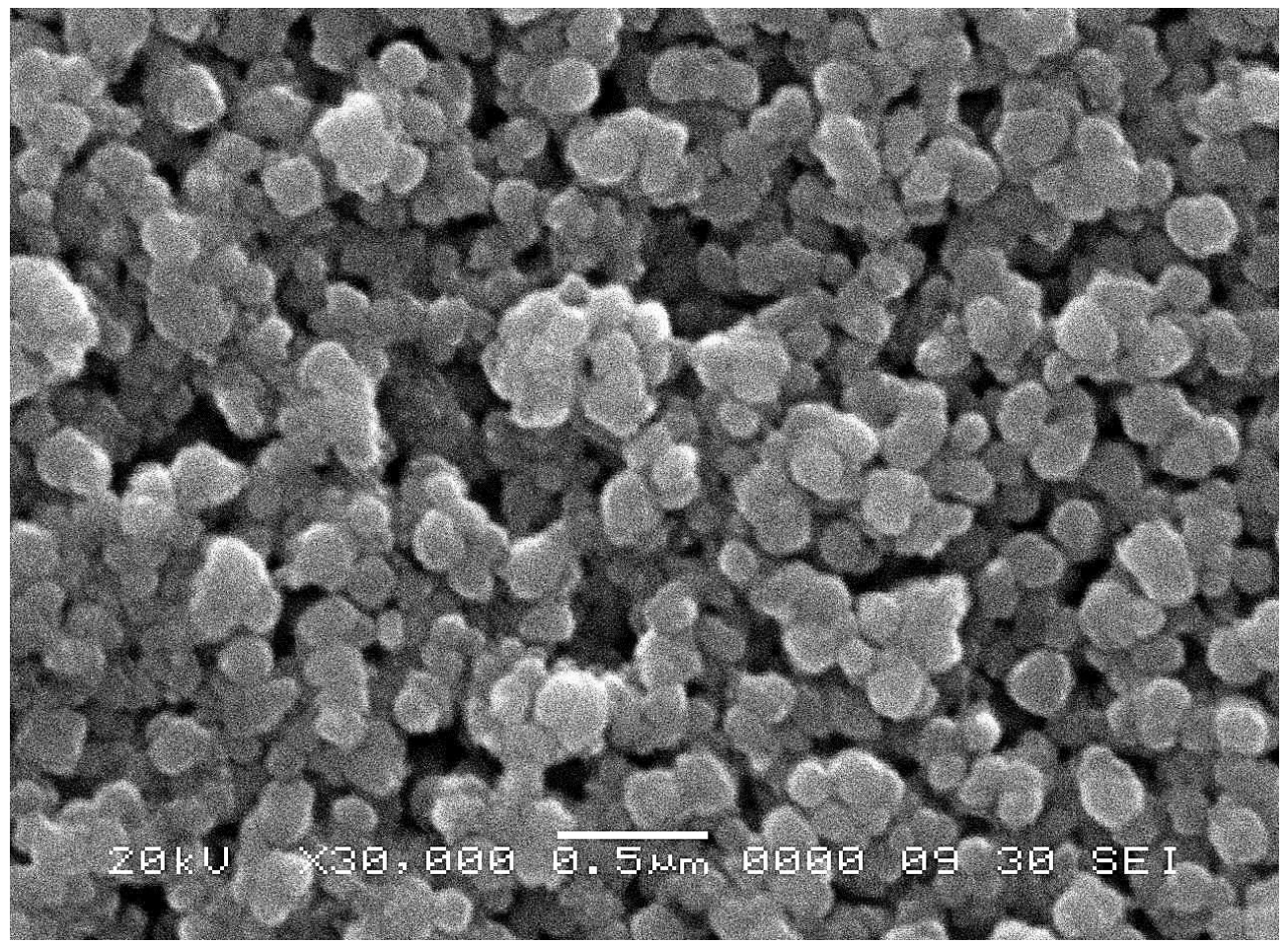

(d)

Fig. 5. SEM images of nanocrystalline CdS thin film samples: (a) S1, (b) S2, (c) S3 and (d) S4. 
SEM micrograph is showing topography of the film surface. The morphology of the grains was roughly spherical in shape. The film compactness was high, the surface's uniformity was good, the particle size was quite fine, and the particle size distribution was also narrow and spherical in shape. The grain size was observed to be increase with increase in deposition temperature as deposition temperature increases amount of solute (i.e. Cadmium sulphate and Thiourea) reaching on the surface of the substrate increase to form and therefore the electrostatic interaction between solute particle become large therefore increasing the probability of more solute particles to be gathered together forming a grain. The observed grain sizes were presented in Table 4.

Table 4. Measurement of deposition temperature, film thickness, crystallite size, grain sizes and optical band gap energy.

\begin{tabular}{|c|c|c|c|c|c|}
\hline Sample & $\begin{array}{c}\text { Deposition } \\
\text { temperature } \\
\left({ }^{\circ} \mathrm{C}\right)\end{array}$ & $\begin{array}{c}\text { Thickness } \\
(\mathrm{nm})\end{array}$ & $\begin{array}{c}\text { Calculated } \\
\text { crystallite } \\
\text { size from } \\
\text { XRD } \\
(\mathrm{nm})\end{array}$ & $\begin{array}{c}\text { Observed } \\
\text { grain size } \\
\text { from } \\
\text { SEM } \\
(\mathrm{nm})\end{array}$ & $\begin{array}{c}\text { Optical band } \\
\text { gap energy } \\
(\mathrm{eV})\end{array}$ \\
\hline S1 & 60 & 650 & 23 & 24 & 3.40 \\
\hline S2 & 65 & 677 & 29 & 30 & 3.34 \\
\hline S3 & 70 & 693 & 39 & 40 & 3.29 \\
\hline S4 & 75 & 705 & 42 & 44 & 3.23 \\
\hline
\end{tabular}

It is clear from Table 4 that as the deposition temperature goes on increase with increase in film thickness, crystallite and grain sizes (which is approximately linear function of the increase in deposition temperature), while optical band gap energy goes on decreases.

\section{5. Quantitative element analysis (EDAX)}

Stoichiometrically expected at \% of $\mathrm{Cd}$ and $\mathrm{S}$ is $50: 50$. The observed at $\%$ of $\mathrm{Cd}$ and $\mathrm{S}$ were presented in Table 5. It is clear from table that as prepared CdS thin films were observed to nonstichoimetric in nature.

Table 5. Quantative elemental analysis as prepared CdS thin film.

\begin{tabular}{|c|c|c|c|c|c|c|c|c|}
\hline \multirow{2}{*}{ Element } & \multicolumn{9}{|c|}{ Observed } \\
\cline { 2 - 9 } & \multicolumn{2}{|c|}{$\mathrm{S} 1$} & \multicolumn{2}{|c|}{ S2 } & \multicolumn{2}{c|}{ S3 } & \multicolumn{2}{c|}{ S4 } \\
\cline { 2 - 9 } & wt $\%$ & at $\%$ & wt $\%$ & at $\%$ & wt $\%$ & at $\%$ & wt \% & at \% \\
\hline Cd & 34.50 & 55.80 & 29.80 & 45.50 & 27.33 & 46.40 & 25.33 & 43.55 \\
\hline S & 66.50 & 54.20 & 70.20 & 54.50 & 72.67 & 53.60 & 74.67 & 56.45 \\
\hline Total & 100.00 & 100.00 & 100.00 & 100.00 & 100.00 & 100.00 & 100.00 & 100.00 \\
\hline
\end{tabular}


Fig. 6 shows the elemental analysis of CdS thin film (sample S3). It was analysed using an energy dispersive spectrophotometer.

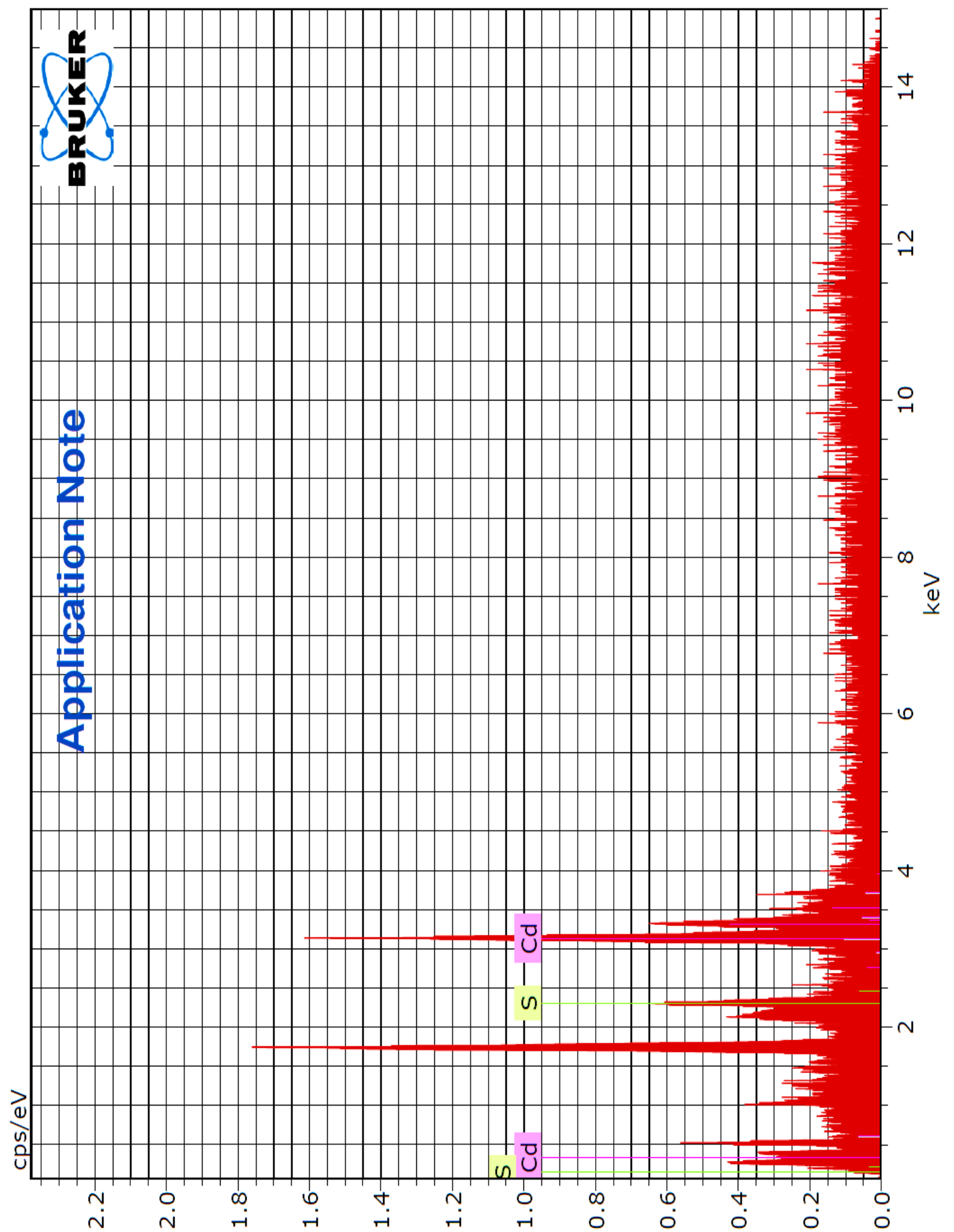

Fig. 6. Elemental analysis of CdS thin film sample (S3). 


\section{6. Electrical properties}

\section{6. 1. Thermoemf measurement}

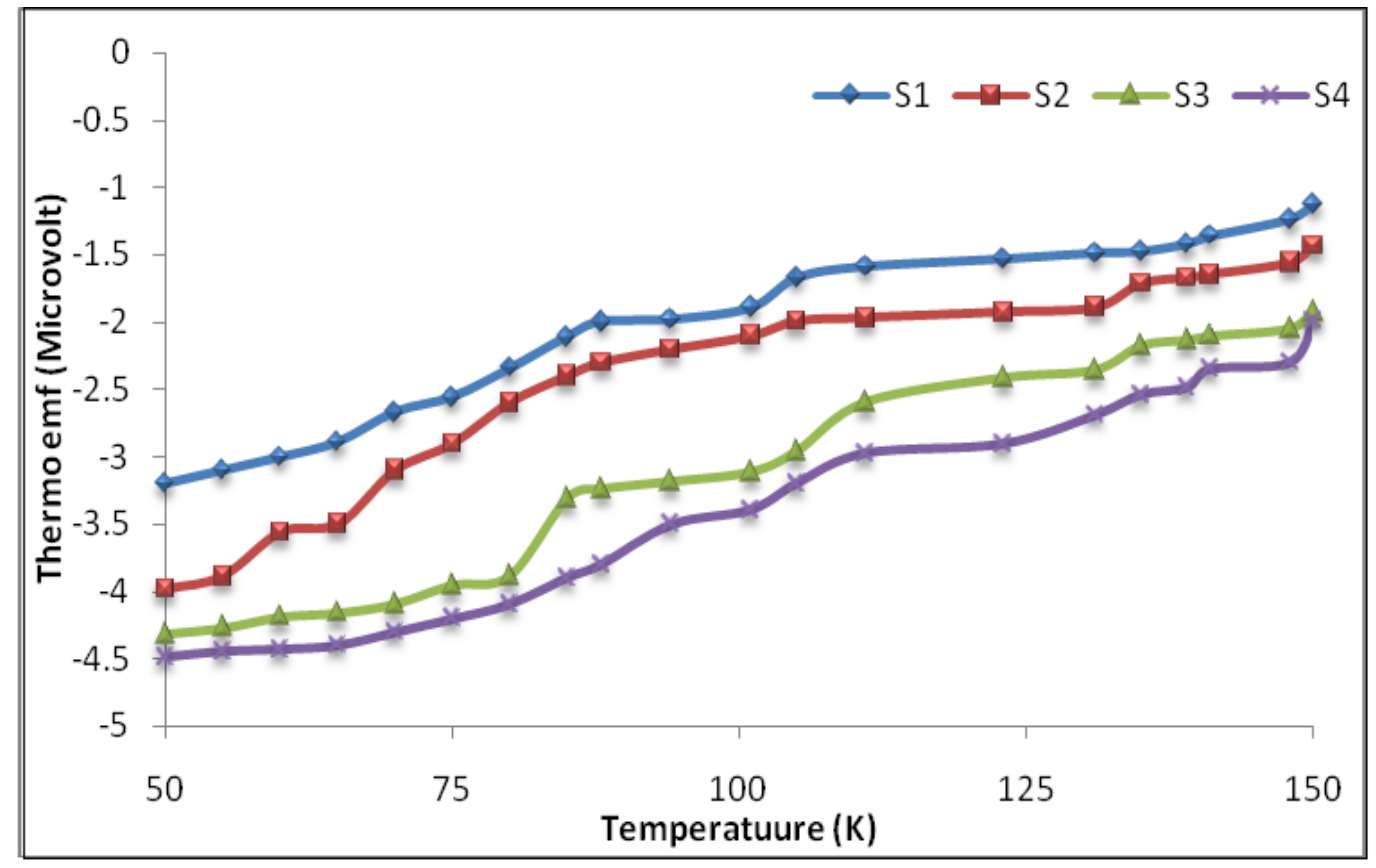

Fig. 7. Thermoemf of nanocrystalline CdS thin films.

In order to decide the type of charge carrier, thermoelectric measurement was taken. The graph of TEP Vs Temperature $(\mathrm{K})$ is as shown in Fig 7. In the thermoemf measurement the temperature difference causes the transport of carriers from hot end to cold end and thus creates an electric field which gives thermal voltage. This thermally generated voltage is directly proportional to the temperature difference created across the semiconductor. The polarity of the thermoemf was positive at the hot end with respect to the cold end which conformed that $\mathrm{CdS}$ films are of n- type. The thermoemf (Figure 7) was measured as a function of temperature in the range between 50 and $150{ }^{\circ} \mathrm{C}$. The variation of the thermoemf with temperature difference for all the samples is shown in Figure. 7.

\section{6. 2. Electrical conductivity}

Conductivity was given by relation

$$
\sigma=\sigma_{\mathrm{o}} \exp (-\Delta \mathrm{E} / \mathrm{kT})
$$

where:

$\sigma=$ conductivity

$\sigma_{0}=$ conductivity constant

$\mathrm{k}=$ Boltzmann constant

$\mathrm{T}=$ Temperature 


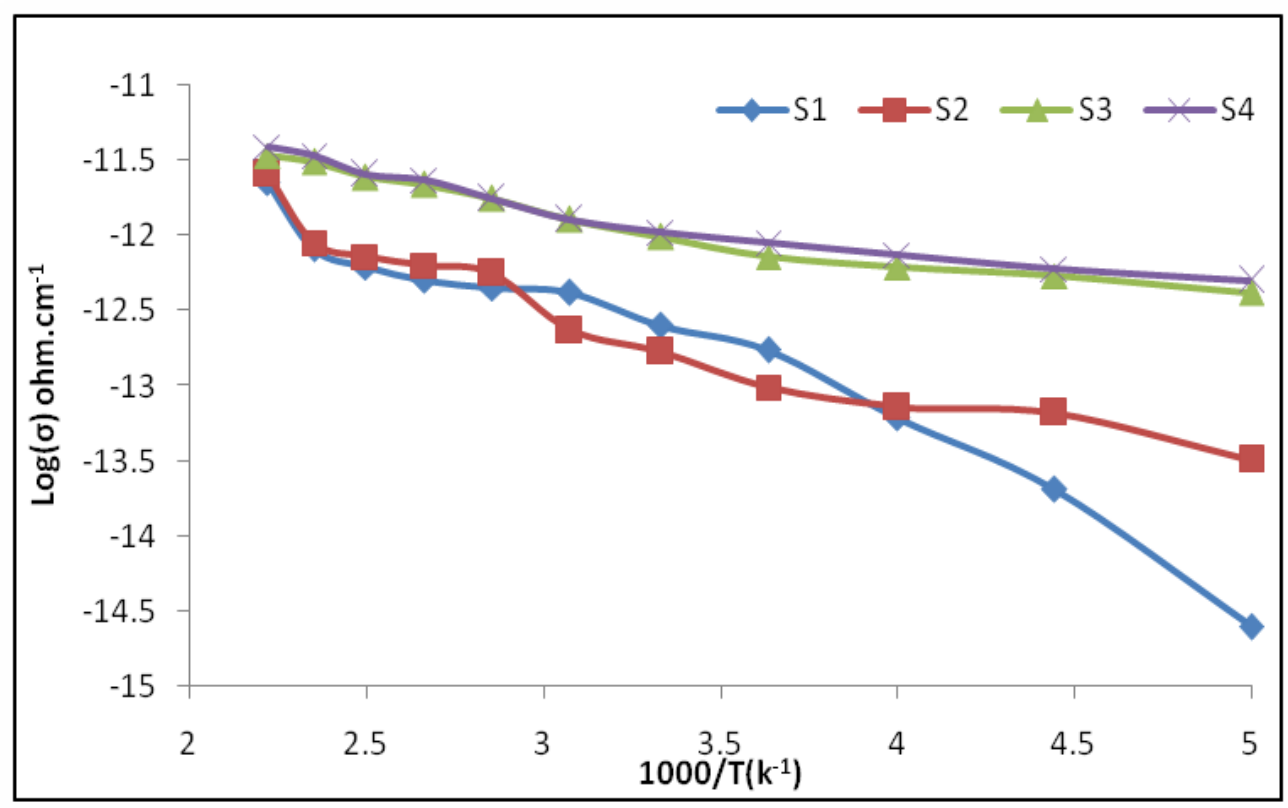

Fig. 8. Variation of $\log (\sigma)$ with $1000 / \mathrm{T}\left(\mathrm{k}^{-1}\right)$.

The conductivity of each sample is observed to be increasing with an increase in temperature. The increase in conductivity with increase in temperature could be attributed to negative temperature coefficient of resistance and semiconducting nature of nanocrystalline CdS. Variation of conductivity with operating temperature (Fig. 8) clearly indicates that the pure nanocrystalline CdS films are semiconducting in nature.

\section{7. Photoconducting application of nanocrystalline CdS thin film in dark and illuminated light with filter and without filter.}

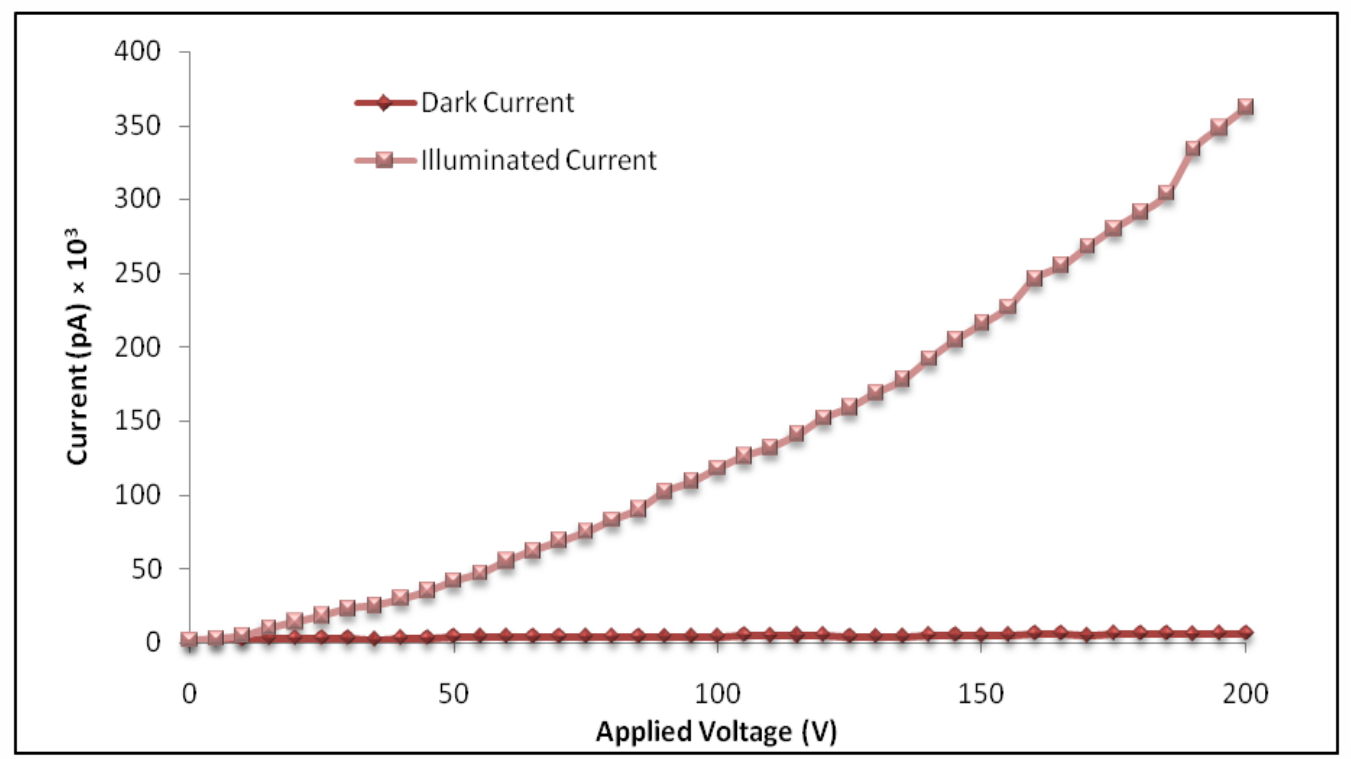

Fig. 9. Variation of photocurrent with in dark light and illuminated light. 
From Figure 9 it was observed that,under dark condition photocurrent is low but it increases when illuminated by light source.

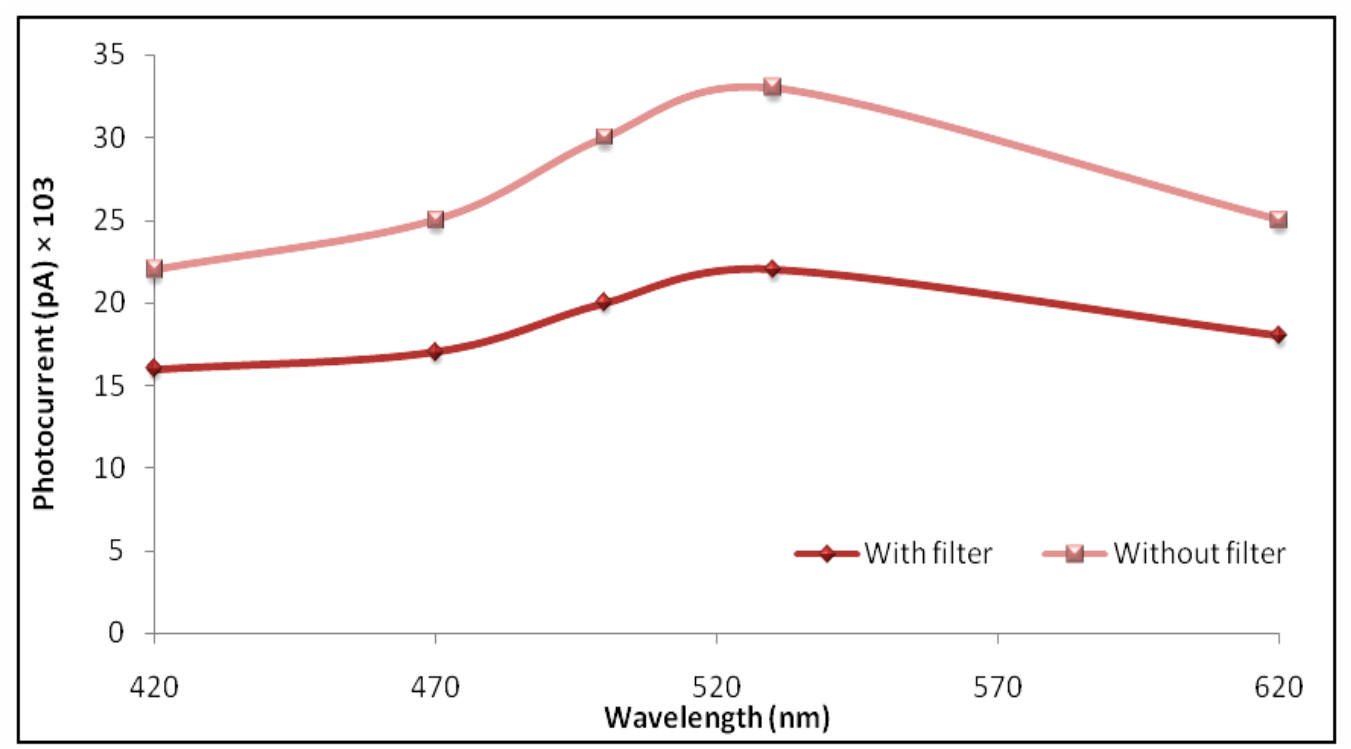

Fig. 10. Variation of wavelength with photocurrent with and without filter.

Above graph shows (Fig. 10) variation of photocurrent for different wavelength of light. It is observed that photocurrent at $530 \mathrm{~nm}$ (green colour) is maximum as compared to other wavelength of light. Finally, it is concluded that intensity of green light is maximum.

\section{CONCLUSIONS}

1) Nanocrystalline $\mathrm{CdS}$ thin films were prepared by simple and inexpensive chemical bath deposition technique.

2) The physical, structural, surface morphological and microstructural properties confirm that the as-prepared $\mathrm{CdS}$ thin films are nanocrystalline in nature.

3) XRD study shows the mixed phase of CdS.

4) The elemental analysis conferred that as prepared thin films were nonstiochiometric in nature.

5) As the chemical bath deposition temperature increases, thickness of the films, crystalline size and grain size goes on increasing while activation energy goes on decreases.

6) Electrical conductivity of the nanocrystalline $\mathrm{CdS}$ thin films were observed to be increased with increase in temperature.

7) TEP measurement indicate that as prepared CdS thin films were n-type in nature.

8) Photoconducting properties shows that as illuminated photocurrent is large as compared to dark current. 


\section{Acknowledgements}

The authors are thankful to Head, Department of Physics and Principal, Z. B. Patil Arts, Science and Commerce College, Dhule for providing laboratory facilities for this work. Thanks to Principal, S. S.M.M. College, Pachora for his encouragement.

\section{References}

[1] Zinoviev K.V., Zeleya-Angel O., Materials Chemistry and Physics 70 (2001) 100-102.

[2] K.D. Dobson, I. Visoly-Fisher, G. Hodes, D. Cahen, Solar Energy Materials \& Solar Cells 62 (2000) 295-325.

[3] X. Wu, Proceedings of the 17th European Photovoltaic Solar Energy Conference, Munich, Germane, October 22-26 (2001) 995-1000.

[4] M. Nagao, S. Watanabe, J. Appl. Phys. 50 (1979) 7247249.

[5] S.A. Mahmoud, A.A. Ibrahim, A.S. Riad, Thin Solid Films 372 (2000) 144-148.

[6] J. Aguilar-Hernandez, et al, Semicond. Sci. Technol. 18 (2003) 111-114.

[7] Ph. Hoffmann, K. Horn, A.M. Bradshaw, R.L. Johson, D. Fuchs, M. Cardona, Phys. Rev. B47 (1993) 1639-1642.

[8] I. K. Battisha, H. H. Afify, G. Abd El Fattah, Y. Badr, Fizika A 11 (2002) 31-42.

[9] A. I. Oliva, O. Solis-Canto, R. Castro-Rodriguez, Quintana, Thin Solid Films 391 (2001) 28-35.

[10] P. K. Nair et al, Solar Energy Materials and Solar Cells, 52 (1998) 313-344.

[11] R. H. Bari, S. B .Patil, A.R. BariI, G. E. Patil, J. Aambekar, Sensors \& Transducers Journal 140 (2012) 124-132.

[12] V. B. Patil, G. S. Shahane, L. P. Deshmukh, Materials Chemistry and Physics 80 (2003) 625.

[13] Hanan R. A. Ali, International Letters of Chemistry, Physics and Astronomy 8 (2014) 47-55.

[14] Raghad Y. Mohammed, S. Abduol, Ali M. Mousa, International Letters of Chemistry, Physics and Astronomy 10 (2014) 91-104

[15] Raghad Y. Mohammed, S. Abduol, Ali M. Mousa, International Letters of Chemistry, Physics and Astronomy 11(2) (2014) 146-158.

[16] JCPDS Data File No. 00-001-0647.

[17] JCPDS Data File No. 00-001-0780. 